\title{
Historical Trends and Variability in Heat Waves in the United Kingdom
}

\author{
Michael G. Sanderson ${ }^{1, *}$ (D) , Theo Economou ${ }^{1,2}$ (D), Kate H. Salmon ${ }^{1}$ and Sarah E. O. Jones ${ }^{1,3}$ \\ 1 Met Office, Exeter EX1 3PB, UK; t.economou@exeter.ac.uk (T.E.); kate.salmon@metoffice.gov.uk (K.H.S.); \\ sarah.jones@jbarisk.com (S.E.O.J.) \\ 2 College of Engineering, Mathematics and Physical Sciences, University of Exeter, Exeter EX4 4QF, UK \\ 3 JBA Risk Management, Skipton BD23 3AE, UK \\ * Correspondence: michael.sanderson@metoffice.gov.uk; Tel.: +44-1392-885680
}

Received: 9 August 2017; Accepted: 25 September 2017; Published: 30 September 2017

\begin{abstract}
Increases in numbers and lengths of heat waves have previously been identified in global temperature records, including locations within Europe. However, studies of changes in UK heat wave characteristics are limited. Historic daily maximum temperatures from 29 weather stations with records exceeding 85 years in length across the country were examined. Heat waves were defined as periods with unusually high temperatures for each station, even if the temperatures would not be considered warm in an absolute sense. Positive trends in numbers and lengths of heat waves were identified at some stations. However, for some stations in the south east of England, lengths of very long heat waves (over 10 days) had declined since the 1970s, whereas the lengths of shorter heat waves had increased slightly. Considerable multidecadal variability in heat wave numbers and lengths was apparent at all stations. Logistic regression, using a subset of eight stations with records beginning in the nineteenth century, suggested an association between the Atlantic Multidecadal Oscillation and the variability in heat wave numbers and lengths, with the summertime North Atlantic Oscillation playing a smaller role. The results were robust against different temperature thresholds.
\end{abstract}

Keywords: heat waves; UK; climate variability; logistic regression; temperature; AMO; NAO

\section{Introduction}

Heat waves, a period of consecutive days with unusually warm temperatures, have a diverse range of impacts on society. Mortality is often elevated, especially in people over 65 years old [1]. Sustained high temperatures during heat waves increase the likelihood of railway tracks buckling, leading to speed restrictions, longer journey times or even closure of the line in extreme cases [2]. In addition, heat waves are often accompanied by droughts, leading to reduced water availability for irrigation and drinking water supplies. River temperatures are often raised during heat waves [3], which can cause serious problems for cooling of power stations. Lower river and lake levels during heat waves can lead to algal blooms, causing mass mortality of fish and birds and posing a serious health threat to both animals and humans [4].

Positive trends in numbers and lengths of heat waves have been found over much of Europe. One study [5] found that average summer heat wave lengths in western Europe had increased by about 1.3 days per century between 1880 and 2005. Another [6] identified an increase in the frequency of heat waves of 0.6 per decade in the Spanish central plateau between 1961 and 2010. In the Southern Alpine region, the lengths of the longest heat waves had increased by 2.7 days per century over the period 1874-2015 [7]. A study of heat waves in Lublin, south east Poland [8], used data recorded over 1951-2015. The number of heat waves over this period had not changed, but heat waves after about 1990 had higher maximum temperatures and longer durations. Significant positive trends in numbers 
of heat wave days and heat wave lengths were identified in many south eastern European cities [9], although the period of data used was fairly short (1980-2015). In a study of heat waves in Ukraine using temperatures recorded over 1951-2011, the largest numbers of heat waves were found in the most recent decade (2001-2010), and the fewest in 1961-1970 and 1971-1980 [10]. In contrast, large variations in numbers of hot days and lengths of heat waves between 1901 and 2003 were found for Basel, Switzerland, but no long-term trends [11].

Only two studies have investigated heat wave trends in the UK, both of which used daily maximum temperatures from the Central England Temperature (CET) record [12]. One study [13] stated that heat waves had become more frequent in May and June over the period 1878-2001, although it was unclear how this conclusion was reached. Another study [5] detected increases in the lengths of the longest heat waves in the CET over a similar period (1880-2005). It is clear from these studies that the full extent of trends in heat wave characteristics and their variations in the UK is not apparent and more investigation is needed. This study aims to understand long-term trends and regional variability in UK heat waves via analysis of heat wave characteristics in the observational record. One issue is the lack of consistent definitions of heat waves which makes comparisons of different studies difficult. A wide variety of heat wave definitions based on single, dual or daily thresholds have been used [14]. In the present study, a simple definition based around a single temperature threshold will be used (Section 2.3).

Previous research has shown that there is a relationship between the Atlantic Multidecadal Oscillation (AMO) and mean summer temperatures in the UK [15]. The AMO is a large-scale pattern of multidecadal variability in sea surface temperatures in the north Atlantic which exerts a considerable influence on global and regional climate [16], with intervals between successive peaks and troughs of several decades [15]. One study [17] suggested that the AMO moderated the lengths of heat waves in western Europe, with longer heat waves corresponding to positive phases of the AMO. In contrast, little effect of the AMO on several extreme high temperature indices was found using data recorded at Sheffield [18]. However, this latter study [18] used a relatively short period of data (1979-2015) and a simple linear correlation, whereas the relationship between the AMO and heat waves or other indices could be non-linear.

Another large scale index which affects summer temperatures in northwest Europe and the UK is the summertime North Atlantic Oscillation (NAO) [19], which may also moderate heat wave numbers and lengths. A significant positive correlation was found between the summertime NAO index and July-August mean temperatures over the UK for the period 1900-2007 [19]. In a study of the effects of many different large-scale atmospheric indices on European climate, the summertime NAO had the highest correlation coefficients with temperatures in July in the UK [20]. The Arctic oscillation had smaller correlation coefficients with July temperatures, and the Polar/Eurasian (POLEUR) and East Asia/Western Russian (EAWR) indices had weaker effects [20]. Other indices studied in [20] had little or no effect on summer temperatures in the UK. The El Niño-Southern Oscillation (ENSO) appeared to have no clear effect on the numbers of warm days between April and October in the UK [21]. However, a more recent analysis [22] of the AMO and ENSO suggested that the ENSO does modulate the number of heat wave days in the UK, although the effect was smaller than that of the AMO.

In addition to analysing the long-term trends and regional variability in numbers and lengths of UK heat waves in the observation records, this study also aims to assess the role that the AMO and summertime NAO may have in moderating these heat wave characteristics.

\section{Experiments}

\subsection{Selection of Stations}

For this study, daily maximum surface air temperatures from weather stations in the UK observation network, which have been continuously operational over the same period for many decades, were required. Any trends in heat wave characteristics in data series of relatively short 
lengths (e.g., a few decades) could be caused by longer-term variations of the climate system. The Met Office Integrated Data Archive System (MIDAS) [23] contains historical and current observations from weather stations around the UK, including data from stations which are no longer operational. MIDAS was initially searched to identify weather stations which were operational at the end of 2016. Some of these stations were active from 1931 or earlier, in theory allowing a period of more than 85 years to be studied. However, records from some stations were shorter than expected as not all the data had been digitised. Some stations were found to have missing data during the warm season (May to September) in multiple years. For example, the record for Bude begins in 1913, but no data are available for 1926-1930 and 1936-1958. Overall, 29 inland and coastal weather stations with near-complete records were selected (Figure 1, Table A1).

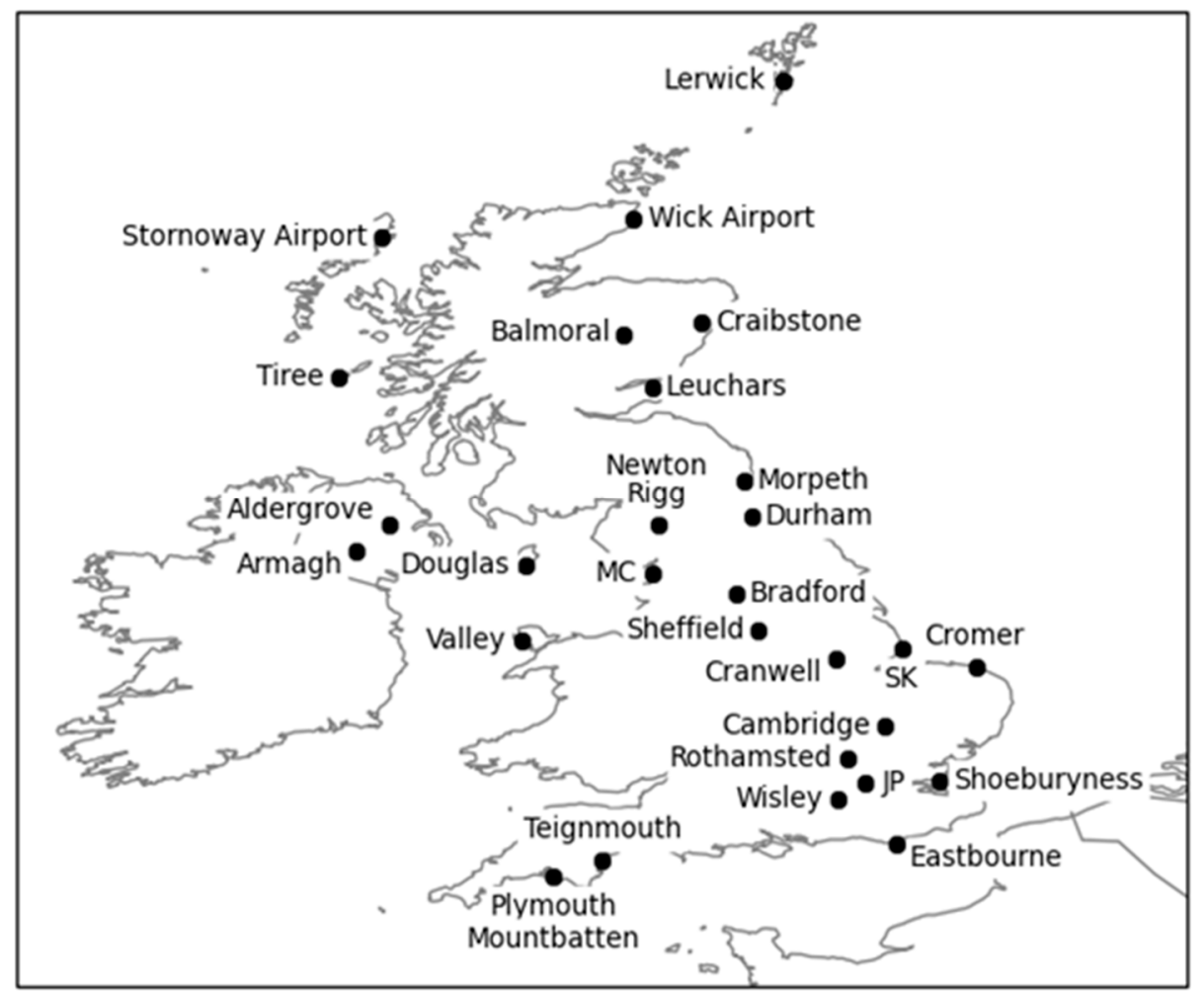

Figure 1. Locations of the 29 weather stations analysed. JP-London, St James's Park; MC-Morecambe; SK-Skegness.

\subsection{Pre-Processing of Station Data}

Some pre-processing was performed to account for changes in reporting types and periods (described in more detail in Supplementary S1 and S2). For example, data at some stations were initially reported every $24 \mathrm{~h}$, but were archived every $12 \mathrm{~h}$ after 1999. In some cases, this modification may have coincided with a change in instrumentation. Data recorded under different types at the same station were joined into a single series (Supplementary S2). For two locations (Plymouth Mountbatten and Shoeburyness), a long series of daily temperatures was created by adjusting and joining records from nearby stations (Supplementary S3). No attempt was made to infill any gaps in the temperature series from any of the stations.

\subsection{Definitions of Hot Days and Heat Waves}

There is no universal definition of a heat wave, and previous studies have used many different thresholds and metrics [14]. Most heat waves are defined as a consecutive number of hot days, where daily mean or maximum temperatures exceed a predetermined threshold. The numbers and 
lengths of heat waves identified will therefore be dependent on the hot day temperature threshold and minimum number of consecutive days; the higher the threshold and/or number of consecutive hot days, the fewer heat waves will be identified [14]. Here, a "hot day" means a day with an unusually high temperature for a given location, even if that temperature would not be considered high in an absolute sense.

In the present study, a hot day threshold was calculated for each station as a percentile of year-round daily maximum temperatures recorded between 1971 and 2000, where any daily maximum temperature reaching or exceeding the threshold is defined as a hot day. Thresholds corresponding to the 90th, 93rd, 95th and 98th percentiles of daily maximum temperatures were calculated for each station. The 90th percentile temperatures were mostly less than $21^{\circ} \mathrm{C}$, which is not exceptionally warm in the UK. This study therefore focuses on heat waves derived from the 93rd, 95th and 98th percentiles, so that the sensitivity of the results to the threshold choice can be assessed. The 93rd and 95th percentiles are considered to be thresholds for moderate heat waves, and the 98th percentile more extreme heat waves. As a result of being station-specific, the 98th percentile thresholds vary across the UK, from $16{ }^{\circ} \mathrm{C}$ at Lerwick in Shetland to $28^{\circ} \mathrm{C}$ in southeast England. The thresholds for most of the stations were above $23^{\circ} \mathrm{C}$. A heat wave was defined as a period with 3 or more consecutive hot days [14]. Although a daily maximum temperature of $16{ }^{\circ} \mathrm{C}$ is not exceptionally warm in an absolute sense, it is for the climate of Lerwick. The occurrence of such temperatures would be expected to be linked with heat waves in other parts of the UK.

Four heat wave metrics were calculated for each year of the temperature records to understand how the climate signal could be manifested: HWN—the number of heat waves; HWD—the length of the longest heat wave; HWF-the total number of heat wave days (or sum of lengths of all heat waves in a year); and HWA—-the highest temperature within a heat wave [14].

\subsection{Analysis of Trends}

A robust method for fitting linear models to the various heat wave characteristics was used to reduce the effects of outliers. The particular method used is based on M-estimators [24]. Briefly, maximum likelihood estimation (MLE) is used to estimate the slope of the fitted line based on a minimising function of the residuals. The fitting was carried out using the Robust Linear Model module which is part of the Python "statsmodels" package. The minimising function was Huber's t. Statistical significance was calculated at the $5 \%$ level.

\subsection{Ocean and Atmospheric Indices}

$\mathrm{AMO}$ and NAO indices have been derived from multiple datasets. In this study, four different series of the AMO and two of the summertime NAO are selected. The statistical modelling (described in Section 2.6) used to assess any influence of the AMO and NAO on heat wave numbers and lengths will be repeated using different combinations of the AMO and NAO datasets. If similar results are obtained regardless of the source of the AMO and NAO, the results would be considered robust.

Time series of the AMO index have been derived from four different global sea surface temperature (SST) datasets (Table S4). Two series were derived from different SST datasets as described in [25], and were downloaded from the KNMI Climate Explorer (available online: https://climexp.knmi.nl/). The AMO has been derived from another SST dataset [26] and was obtained from the NOAA/OAR/ESRL PSD, Boulder, Colorado, USA (available online: https: / / www.esrl.noaa.gov/psd/data/timeseries/AMO/). A fourth AMO time series for 1870-2016 was calculated from the HadSST3 dataset [27] using data for the Atlantic between $20^{\circ} \mathrm{N}-60^{\circ} \mathrm{N}$. Before use, all the AMO data were smoothed with a Chebyshev filter of order 2 and a cut off frequency of 12 years to emphasise the multidecadal variability [28].

Two series of the summertime NAO indices, derived from a sea level pressure reconstruction [29] and the twentieth century reanalysis [30] were obtained from the KNMI Climate Explorer. In both cases, the NAO was the principle component of the first empirical orthogonal function of sea level 
pressure over the region $40^{\circ} \mathrm{N}-70^{\circ} \mathrm{N}$ and $90^{\circ} \mathrm{W}-30^{\circ} \mathrm{E}$ (Table S4). The two NAO datasets contain monthly values. The summertime NAO used in the present study was the mean of the values for July and August. The summertime NAO data were smoothed using a binomial filter with a half period of 25 years [19]. The smoothed AMO and summertime NAO series are shown in Figure A1.

\subsection{Logistic Regression across Multiple Stations}

Logistic regression will be used to quantify any possible effect of the AMO and summertime NAO on the numbers and lengths of heat waves in the UK. When considering numbers of heat waves, for example, a variable of interest, $y(t)$, is defined as an event with more than a prescribed number $n$ of heat waves in a year. $y(t)$ is binary with $y(t)=1$ if $n$ or more heat waves occurred in year $t$, and $y(t)=0$ otherwise. Years with no heat waves are included and $y(t)=0$ in those years. In the equations below, $\mathrm{AMO}(\mathrm{t})$ and $\mathrm{NAO}(\mathrm{t})$ are the smoothed annual mean $\mathrm{AMO}$ and summertime NAO indices for year $\mathrm{t}$.

The baseline model used to explain the probability that $n$ or more heat waves would occur in a given year is a Bernoulli Generalised Linear Model (GLM), where:

$$
\begin{gathered}
p(t)=\text { probability that } y_{j}(t)=1 \text { at station } j=1, \cdots, 8 \\
\log \left(\frac{p_{j}}{1-p_{j}}\right)=\alpha+\beta A M O(t)+\gamma N A O(t)
\end{gathered}
$$

This approach is the conventional way of modelling binary data, where the logarithm of the odds ratio $p(t) /(1-p(t))$ (called the log-odds ratio) is modelled as a linear function of the explanatory variables. Positive values of the log-odds ratio correspond to probabilities greater than one half, and negative values to probabilities below one half. Hence both positive and negative values of the parameters $\beta_{j}$ and $\gamma_{j}$ are possible.

In order to pool all the data together across multiple stations, but at the same time allow each station to have a potentially different AMO and NAO effect, the model is extended so that $\alpha, \beta$ and $\gamma$ are treated as random variables:

$$
\begin{gathered}
p_{j}(t)=\text { probability } \text { that } y_{j}(t)=1 \text { at station } j=1, \cdots, 8 \\
\begin{aligned}
\log \left(\frac{p_{j}(t)}{1-p_{j}(t)}\right) & =\alpha_{j}+\beta_{j} A M O(t)+\gamma_{j} N A O(t) \\
\alpha_{j} & \sim \operatorname{Normal}\left(0, \sigma_{\alpha}^{2}\right) \\
\beta_{j} & \sim \operatorname{Normal}\left(\mu_{\beta}, \sigma_{\beta}^{2}\right) \\
\gamma_{j} & \sim \operatorname{Normal}\left(\mu_{\gamma}, \sigma_{\gamma}^{2}\right)
\end{aligned}
\end{gathered}
$$

where $\mu_{\beta}$ and $\mu_{\gamma}$ are the average effects of the AMO and summertime NAO respectively across the stations. The individual effects $\beta_{j}$ and $\gamma_{j}$ are deviations from those means, but it should be noted that they are constrained by the common variances $\sigma_{\beta}^{2}$ and $\sigma_{\gamma}{ }^{2}$. Constraining the individual responses in this way allows information across the stations to be pooled, whilst maintaining enough flexibility for each station to have a unique $\mathrm{AMO}$ and $\mathrm{NAO}$ effect due to measurement discrepancies or the two drivers having a different effect across the UK.

The model parameters are estimated in a Bayesian framework using a Markov Chain Monte Carlo (MCMC) method, using the statistical software R [31], and specifically the package "rjags" [32]. Inference in the Bayesian framework is based on the posterior distribution of each model parameter, from which one obtains samples when fitting the model using MCMC. The posterior distributions express uncertainty in the model parameters and direct probabilistic statements can be made to assess significance. For instance, noticing that zero is not included in the $95 \%$ Credible Interval (CrI) of 
a parameter, it may be concluded that the parameter is "significantly different from zero" in the classical sense.

\section{Results}

\subsection{Analysis of First and Last Heat Wave Days}

The dates of the first and last heat wave days at the stations shown in Figure 1 were recorded. Most of the heat wave days occurred between May and September. However, heat waves were also identified in April and October at some of the stations during a few years. Hence, temperatures within an extended warm season, April to October, were used to identify heat waves at all stations.

Heat waves might appear earlier and end later in the year as the climate warms. Trends in the first and last days of year belonging to a heat wave were calculated for each weather station and temperature threshold for the period 1961-2016. Most of the trends in the first days were negative when the 93rd or 95th percentile thresholds were used (suggesting that moderate heat waves were appearing earlier in the year), but, with the exceptions of Eastbourne and Teignmouth, none were significant at the $5 \%$ level (data not shown). Most of the trends using the 98th percentile threshold were positive (at 22 out of 29 stations) but none (positive or negative trends) were significant, except at Cromer, where a positive trend was found.

In contrast, significant positive trends in the last days of year belonging to heat waves were found at nine stations for the 93rd and at eight stations for the 95th percentile thresholds (Table S5.1). This result suggests heat waves have occurred later in the year in south east England over last five decades. Negative trends were found at a small number of stations but none were significant. When the 98th percentile threshold (representing extreme heat waves) was used, twelve of the trends were positive and the rest were negative (Table S5.1). Only the trends at Cromer (positive) and Wisley (negative) were significant.

\subsection{Heat Wave Characteristics}

The median and interquartile ranges of numbers of heat waves (HWN), longest heat waves (HWD), annual total of heat wave days (HWF) and hottest day during a heat wave (HWA) are shown in Table 1 using the 95th percentile thresholds. The median numbers of heat waves are similar across the stations, 2 or 3 . The medians of the longest heat waves (HWD) are also similar. Greater variation is seen in sums of lengths of heat waves (HWF) and the maximum temperatures in the heat waves (HWA).

Table 1. Median and interquartile ranges of numbers of heat waves (HWN), longest heat waves (HWD), annual numbers of heat wave days (HWF) and highest temperatures in the heat waves (HWA) using data for 1931-2016. The temperature thresholds used to identify heat waves were the 95th percentiles.

\begin{tabular}{ccccc}
\hline Station & HWN & HWD & HWF & HWA \\
\hline Aldergrove & $2[1-3]$ & $5[4-7]$ & $10[6-14]$ & $25.2[24.0-27.2]$ \\
Armagh & $2[1-3]$ & $5[4-8]$ & $10[7-16]$ & $26.0[25.0-27.6]$ \\
Balmoral & $2[1-3]$ & $5[4-7]$ & $9[6-14]$ & $25.6[24.7-27.5]$ \\
Bradford & $2[1-3]$ & $5[4-7]$ & $8[6-16]$ & $27.2[26.1-28.3]$ \\
Cambridge, Botanical Gardens & $2[1-3]$ & $6[4-7]$ & $10[5-15]$ & $30.6[29.4-32.4]$ \\
Craibstone & $2[1-3]$ & $5[3-6]$ & $9[4-14]$ & $24.9[23.3-25.6]$ \\
Cranwell & $2[1-4]$ & $5[4-8]$ & $10[6-18]$ & $30.0[28.6-31.7]$ \\
Cromer & $2[2-3]$ & $4[3-6]$ & $10[6-14]$ & $29.0[27.1-30.9]$ \\
Douglas & $2[1-4]$ & $5[4-8]$ & $12[6-18]$ & $24.4[22.8-25.5]$ \\
Durham & $2[1-4]$ & $5[4-7]$ & $10[5-17]$ & $27.2[25.6-29.0]$ \\
Eastbourne & $2[1-4]$ & $6[4-8]$ & $11[6-18]$ & $26.5[25.6-27.8]$ \\
Lerwick & $2[2-4]$ & $6[4-9]$ & $12[7-20]$ & $18.9[17.5-20.6]$ \\
Leuchars & $2[1-3]$ & $4[3-6]$ & $7[4-14]$ & $25.4[24.4-27.2]$ \\
London, St James's Park & $2[1-4]$ & $6[4-8]$ & $11[6-17]$ & $30.9[29.4-32.8]$ \\
Morecambe & $2[2-3]$ & $5[4-8]$ & $10[6-16]$ & $27.6[25.6-28.9]$ \\
Morpeth & $2[1-4]$ & $5[3-7]$ & $9[6-17]$ & $25.3[24.4-27.2]$ \\
Newton Rigg & $2[1-34]$ & $6[4-8]$ & $11[7-16]$ & $27.0[25.4-28.3]$ \\
\hline
\end{tabular}


Table 1. Cont.

\begin{tabular}{ccccc}
\hline Station & HWN & HWD & HWF & HWA \\
\hline Oxford & $2[1-3]$ & $5[4-8]$ & $10[6-16]$ & $30.0[28.7-31.6]$ \\
Plymouth Mountbatten & $2[1-3]$ & $5[4-7]$ & $9[5-14]$ & $25.8[24.8-27.4]$ \\
Rothamstead & $2[1-3]$ & $5[4-7]$ & $10[6-14]$ & $29.4[27.8-30.7]$ \\
Sheffield & $2[1-3]$ & $5[4-6]$ & $8[5-13]$ & $28.6[27.7-30.2]$ \\
Shoeburyness & $3[2-4]$ & $5[4-8]$ & $12[6-19]$ & $28.0[27.1-29.5]$ \\
Skegness & $2[1-3]$ & $4[3-6]$ & $8[5-13]$ & $27.2[25.8-28.4]$ \\
Stornoway Airport & $3[1-4]$ & $6[4-8]$ & $14[7-20]$ & $22.2[20.6-23.3]$ \\
Teignmouth & $2[1-4]$ & $5[3-8]$ & $10[6-19]$ & $25.6[24.6-27.2]$ \\
Tiree & $2[1-3]$ & $5[4-9]$ & $9[5-17]$ & $22.4[20.5-23.8]$ \\
Valley & $2[1-3]$ & $4[3-8]$ & $8[4-7,16]$ & $27.1[25.2-28.2]$ \\
Wick Airport & $2[1-3]$ & $4[3-6]$ & $7[4-14]$ & $21.7[20.5-22.9]$ \\
Wisley & $2[1-4]$ & $6[4-8]$ & $10[6-17]$ & $30.6[29.0-32.2]$ \\
\hline
\end{tabular}

\subsection{Trends in Heat Waves}

Trends in heat wave numbers (HWN), longest lengths (HWD) and sums of lengths (HWF) for all three thresholds are illustrated in Figure 2a-c for 1961-2016. None of the trends in the heat wave metrics based on the 98th percentile were significant, whereas many trends based on the 93rd and 95th percentiles were significant. These findings suggest that moderate heat waves have increased in number and length from 1960, but any changes in the most extreme heat waves are unclear. These results are in qualitative agreement with other studies $[5,7,13]$. The stations with significant trends in heat wave numbers (Figure 2a) are spread around the UK. In contrast, the stations with significant trends in heat wave lengths (Figure 2b,c) are mostly located in south east England and the islands around Scotland.

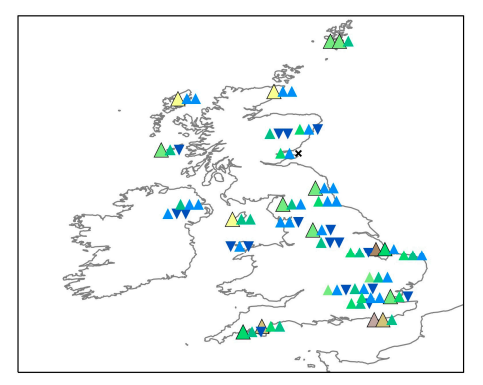

(a)

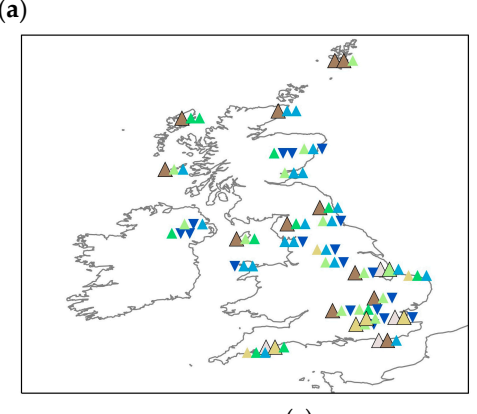

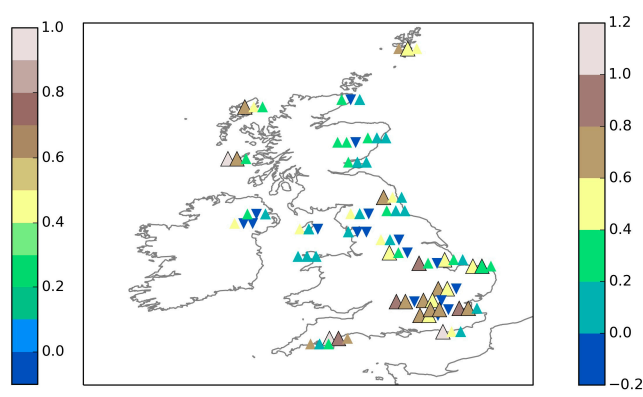

(b)

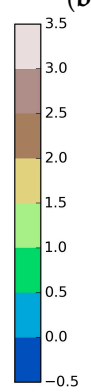

(c)

Figure 2. (a) Trends in numbers of heat waves (HWN) per decade over 1961-2016. The three symbols for each station are (from left to right) the trends using the 93rd, 95th and 98th percentile thresholds. Upward and downward-pointing triangles indicate positive and negative trends respectively. Large symbols with a border indicate trends significant at the $5 \%$ level; non-significant trends are shown by small symbols without a border. The trend values are indicated by the colour bar. The ' $x$ ' at Leuchars indicates a trend could not be calculated; (b) As (a), but trends in lengths of longest heat waves (HWD) per decade over 1961-2016; (c) As (a), but trends in total numbers of heat wave days (HWF) per decade over 1961-2016. 
The trend values for the three heat wave metrics are listed in Tables S5.2-S5.4 for each threshold over two time periods, 1931-2016 and 1961-2016. Generally, few of the trends are significant at the 5\% level for 1931-2016, whereas more are significant for 1961-2016.

However, the changes in lengths of longest heat waves (HWD) are more complex than suggested by a simple analysis of trends. Heat waves longer than 8-12 days (depending on the station) were very rare before the 1970s, and only occurred in 1911, 1921 and 1947. From 1976, these longer heat waves were present in most or all of the years 1976, 1983, 1990, 1995, 1997, 2003, 2006, 2011 and 2013 (Figure 3).

There is a marked difference in the changes in lengths of heat waves up to 11 days in length and those with longer lengths when the 93rd and 95th percentile thresholds are used for some stations in southern and eastern England (Cambridge, Durham, Eastbourne, Morecambe, London St James' Park and Wisley). As an example, the longest heat waves in each year (HWD) are shown in Figure 3 for London St James's Park. Heat waves with lengths of 11 days or less (below the dotted line) declined in range between the 1930 and 1970 from 3-10 days to 3-7 days, after which the range increased slightly to 3-9 days. In contrast, the lengths of very long heat waves (those above the dotted line) declined from a high point in the mid-1970s (about 22 days) to 12-13 days in the 2010s. This decline is shown by the solid grey line. The reasons for the decline in lengths of very long heat waves are unclear.

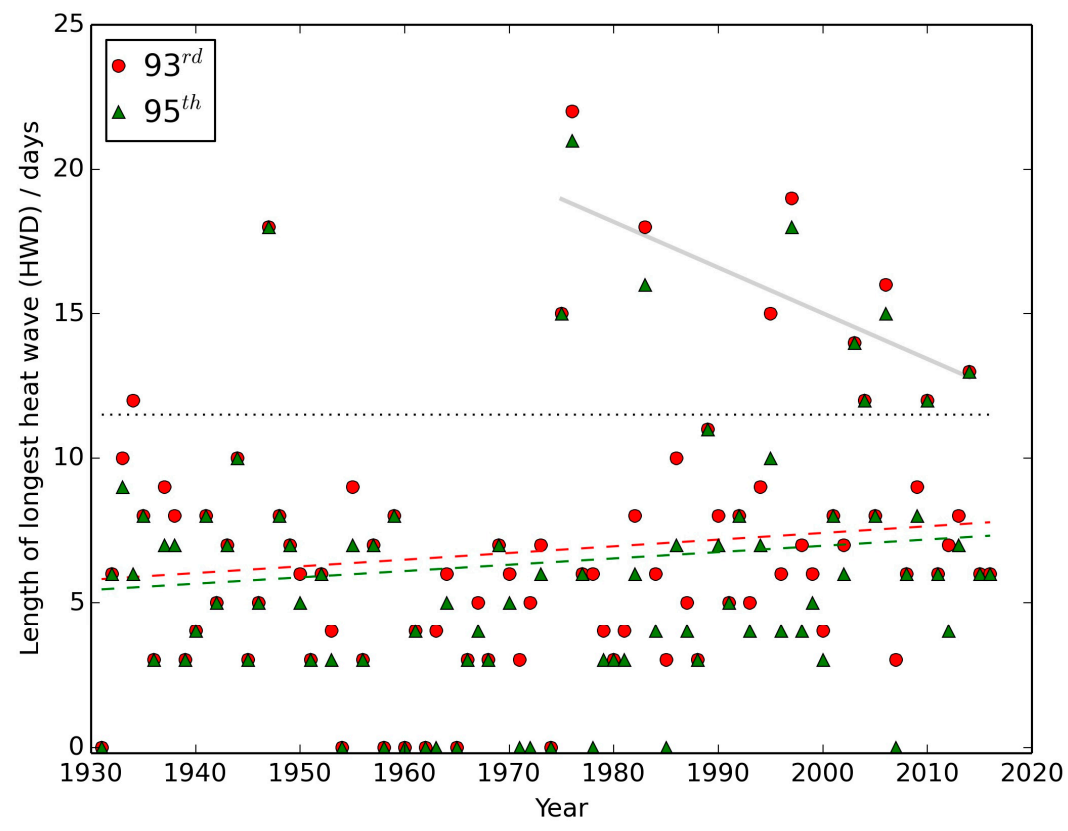

Figure 3. Lengths of longest heat waves (days) for St James's Park, London. Heat waves are defined as 3 or more consecutive days when daily maximum temperatures reach or exceed the 93rd (red circles) or 95th (green triangles) percentile of year-round temperatures over 1971-2000. The red and green dashed lines indicate linear trends fitted to the whole data. The boundary defining very long heat waves (12 days or more) is shown by the horizontal dotted line. The solid grey line illustrates the downward trend in lengths of very long heat waves from 1975.

The directions of change in lengths of very long heat waves (i.e., those above the dotted line in Figure 3) are shown in Figure 4 using heat waves associated with the 93rd percentile threshold. A decline in the length of the very long heat waves is seen for stations in south east England. When the 95th percentile threshold is used, any changes in the lengths of the very long heat waves were less clear, but those showing the clearest decreases were also located in the south east of England. 


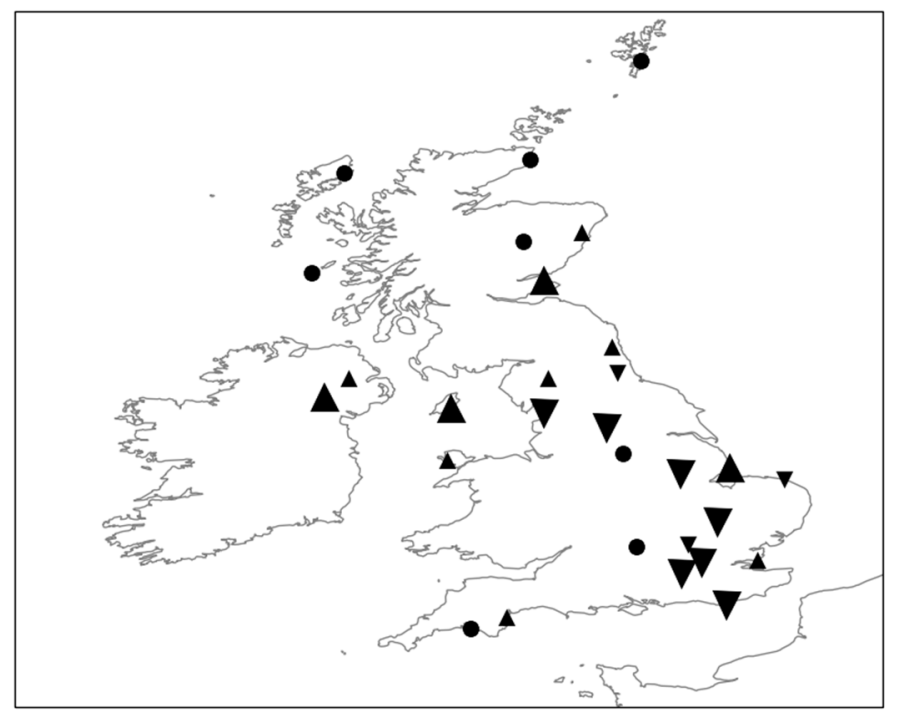

Figure 4. Direction of change in lengths of very long heat waves (longer than 8-12 days, depending on the station) at each station using the 93rd percentile thresholds. Upward- and downward-pointing triangles indicate an increase and decrease in the lengths respectively. Large symbols indicate a clear change, whereas small symbols show a small change. A solid circle indicates no clear direction of change in the lengths.

\subsection{Variations in the AMO, Summertime NAO and Heat Wave Characteristics}

Positive trends in heat wave numbers and lengths have been identified for many of the stations in Figure 1 (Section 3.3). However, considerable multidecadal variability is evident in the numbers and lengths of heat waves (Figure A2). Variations in the sign and magnitude of the AMO could be responsible for modulating heat wave lengths [5].

A comparison by eye of the smoothed annual mean $\mathrm{AMO}$ and $\mathrm{NAO}$ anomalies and time series of numbers of heat waves (Figure A2) suggests that when the AMO or NAO is in a positive phase, there are generally greater numbers of heat waves. In contrast, when the AMO or NAO is in a negative phase, there are generally fewer heat waves. In Figure A2, years with 1 or 2 heat waves are reasonably common, but years with 3 or more heat waves are notably smaller in number, with these events typically occurring during a positive phase of the AMO and/or NAO.

\subsubsection{Effects on Numbers of Heat Waves}

Logistic regression was used to quantify the possible effect of the AMO and summertime NAO on the numbers of heat waves in the UK. The AMO and summertime NAO records are available from the mid-19th century (Table S4). Eight weather stations with records beginning in the 19th century (Armagh, Douglas, Durham, Morpeth, Oxford, Plymouth, Sheffield and Stornoway Airport; Table A1) were therefore selected to maximise the overlap with the AMO and NAO datasets and hence numbers of years for study. The logistic regression used all available data, so that the periods differed slightly depending on the combination of AMO and summertime NAO datasets (Table S4).

Results using the AMO from HadSST3 [27] and summertime NAO derived from the sea level pressure (SLP) data of Trenberth and Paolino [29] are shown in Figure 5, using heat wave numbers derived using the 95th percentile threshold. The individual effects for each station $\beta_{j}$ and $\gamma_{j}$ (defined in Equations (6) and (7)) and their 95\% CrIs are indicated by the solid circles and horizontal lines respectively. The average effects across all stations $\left(\mu_{\beta}\right.$ and $\mu_{\gamma}$ in Equations (6) and (7)) and their respective $95 \%$ CrIs are illustrated by the vertical solid and dashed lines. The results shown in Figure 5 a suggest that there is a positive effect of the AMO on the log-odds ratio of three or more heat waves with some small variability between stations, although the effect at Stornoway is weaker than the other 
stations. The mean AMO effect across all stations is 1.41 with $\mathrm{CrI}[0.53,2.26]$. The overall effect of the summertime NAO is also positive (Figure $5 b$ ) but smaller than the AMO effect, and appears to be weaker at Oxford and Stornoway than the other locations. Overall, the results in Figure 4 suggest that variations in the AMO and summertime NAO moderate the numbers of heat waves, with a higher probability of larger numbers during positive phases of both indices.
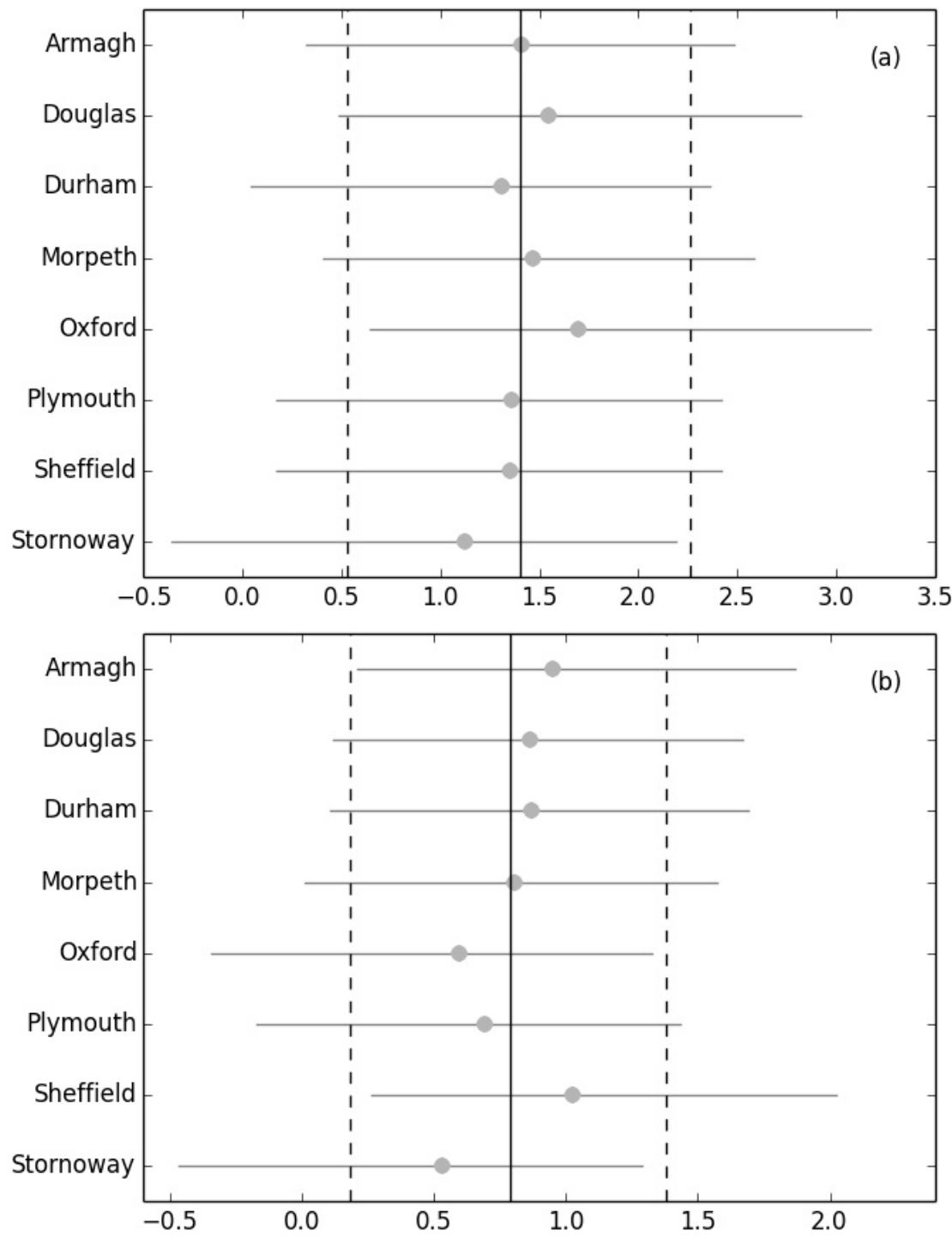

Figure 5. Modelled effects of (a) the Atlantic Multidecadal Oscillation (AMO) and (b) summertime North Atlantic Oscillation (NAO) on the probability of 3 or more heat waves in a year, using the 95th percentile threshold to define heat waves. The individual effects (corresponding to the parameters $\beta_{j}$ (panel a) and $\gamma_{j}$ (panel b) in Equations (6) and (7) above) and their 95\% confidence intervals are shown by the solid grey circles and lines respectively. The mean effects across all eight stations (parameters $\mu_{\beta}$ (panel a) and $\mu_{\gamma}$ (panel b) in Equations (6) and (7)) and associated 95\% confidence intervals are shown by the vertical solid and dashed lines respectively. Note that ranges of the effects in the two panels (values along the $x$-axis) are different.

The analysis above was repeated using heat waves derived using the 93rd and 98th percentile thresholds. The mean effects of the AMO and summertime NAO across all eight stations are shown in Figure 6 for all combinations of the AMO and NAO datasets and the three percentile thresholds. Overall, the results are consistent across the percentile choice. Any changes in the magnitudes of the effects between thresholds are small and none have changed sign. The size of the AMO effect remains 
greater than the summer NAO effect. The CrIs using the 98th percentile thresholds are larger than the CrIs for the lower thresholds, and some include zero, although most of the masses of the distributions lie above zero. The deviations between the percentile thresholds are probably caused by randomness in sampling the data.
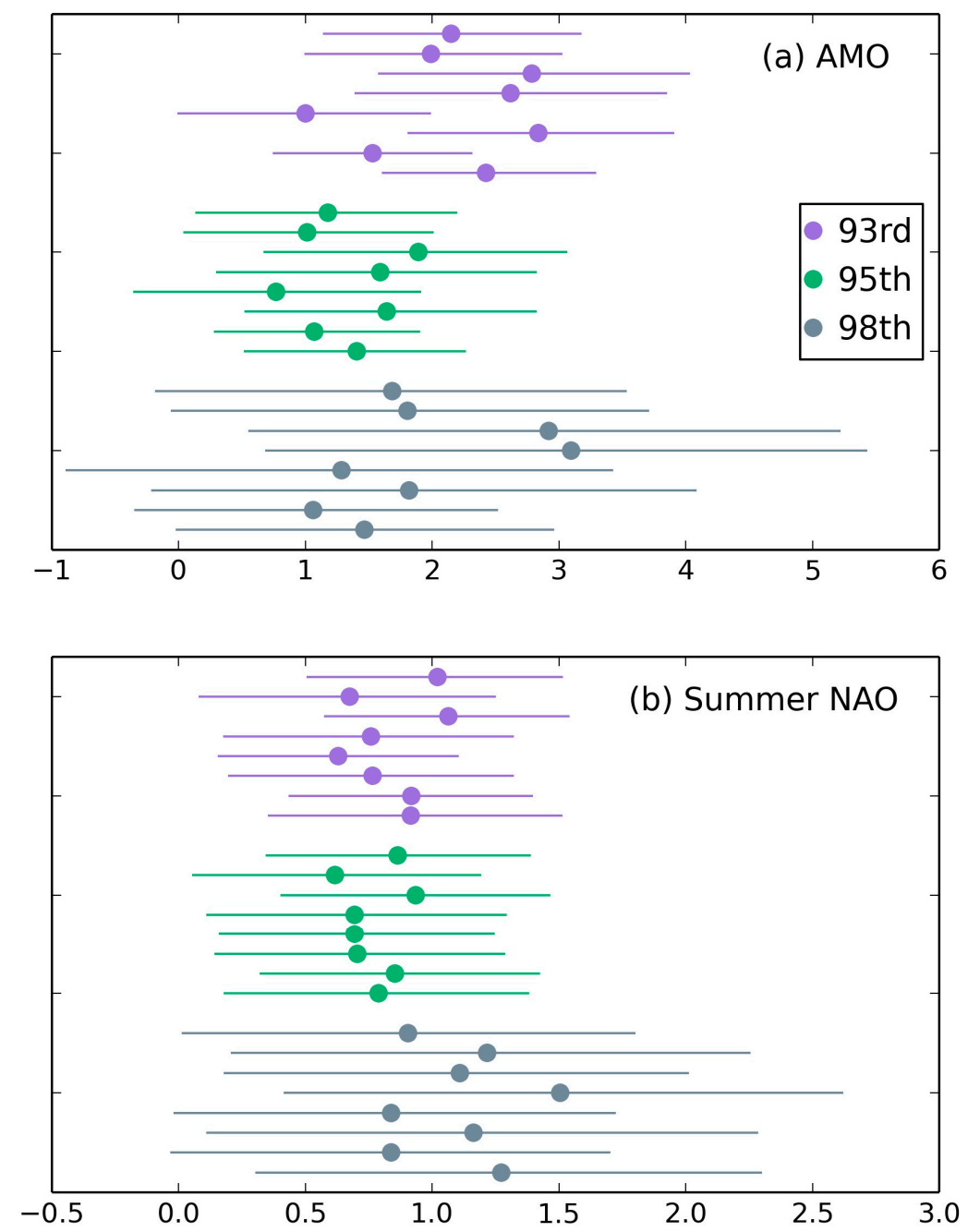

Figure 6. Mean effects of (a) the AMO and (b) summertime NAO (corresponding to parameters $\mu_{\beta}$ and $\mu_{\gamma}$ in Equations (6) and (7) respectively) on the probabilities of 3 or more heat waves in a year across eight stations using three different percentile-based thresholds. Four AMO and two NAO datasets were used, giving eight combinations (Table S4). The solid circles show the mean effects and the horizontal lines the $95 \%$ confidence intervals.

\subsubsection{Logistic Modelling of Heat Wave Lengths}

The logistic model was fitted to the longest heat waves (HWD) for each station. Threshold lengths of 8 and 10 days were used based on an inspection of the lengths identified for the weather stations. The mean effects across all eight stations are shown in Figures S6.1 and S6.2. For the threshold of 8 days (Figure S6.1), the AMO effects were mostly in the range 1.0-2.0 and were consistent across the different combinations of $\mathrm{AMO}$ and summer $\mathrm{NAO}$ datasets and heat wave temperature thresholds. The CrIs of the effects for the 98th percentile thresholds were broader and included zero but were consistent with the results using the lower percentile thresholds. This result suggests that the AMO may also moderate heat wave lengths. 
The summer NAO effects were smaller (range 0.5-1.0) and had similar magnitudes when the 93rd and 95th percentile thresholds were used, but some of the CrIs included zero. The effects using the 98th percentile threshold were notably larger (2.0-3.5) and none of the CrIs included zero, although the CrIs were also wider. The estimated effects using the summer NAO derived from the SLP data of Trenberth and Paolino (Table S4) were smaller than when the NAO derived from the $20 \mathrm{CR}$ data were used, which may be related to the differing lengths of the two sea level pressure datasets (Table S4). It is tentatively concluded that the summer NAO might moderate the lengths of extreme heat waves, but possibly has less effect on moderate heat waves. When a threshold length of 10 days was used, the results were similar, but more of the CrIs included zero (Figure S6.2).

\section{Discussion}

\subsection{Heat Wave Metrics}

Numbers and lengths of heat waves calculated from weather station records in the UK were found to be highly variable over time. The median numbers and lengths (Table 1) for stations in or close to London and in Northern Ireland were similar to those calculated for London and Dublin using a different heat wave definition [9]. Positive trends in numbers and lengths of longest heat waves were identified at many stations using data from 1961. These results are consistent with the anthropogenic climate warming signal [33]. Studies of heat waves using temperatures recorded in continental Europe identified positive trends in numbers and lengths of heat waves since the end of the nineteenth century $[5,7]$.

However, the lengths of heat waves at some stations in the UK were found to fall into two groups. Heat waves with lengths less than about 11 days occur throughout the data series, and the range of longest lengths fell from 3-10 to about 3-7 days between 1931 and 1970 before increasing slightly to 3-9 days by 2016. In contrast, very long heat waves (longer than 11 days) were very rare at most stations until the mid-1970s. Since this time, these very long heat waves have been more common, but their lengths at stations in central and south east England have declined, from around 20 days to 12 days. The reasons for the different directions of changes in these two groups of heat wave lengths is unclear.

\subsection{Circulation and SST Influences}

Considerable multidecadal variability in both the numbers and lengths of heat waves was apparent at all stations. Logistic regression was used to quantify the possible effect of the AMO and summertime NAO on heat wave numbers and lengths. The results suggested that higher numbers and lengths of heat waves in the UK are associated with the positive phase of the AMO. Smaller numbers and lengths of heat waves tend to occur when the AMO is in a negative phase. The exceptions were the long heat waves of 1975 and 1976, which were probably exacerbated by an accompanying drought. The logistic regression also suggested that the summertime NAO moderates numbers and lengths of heat waves, although its influence was smaller than that of the AMO. These results were robust across three different temperature thresholds used to define heat waves. The exact magnitudes of the effects of the AMO and summertime NAO on heat wave numbers were dependent on the particular datasets chosen. Overall, the conclusions are not sensitive to the choice of threshold, or the particular AMO and NAO datasets employed.

\subsection{Limitations and Further Work}

Only two cycles of the AMO have been observed directly, so the results in the present study should be regarded as preliminary. The AMO and NAO were treated as independent variables in the logistic regression. The exact cause of the AMO and the possible role of the NAO in controlling the AMO is not fully understood, with both internal variability of the ocean circulation and external forcing playing a role [34]. It is noted that another study [17] suggested that global mean temperature 
changes might be driving the variability in heat wave numbers and lengths instead of the AMO and NAO. Identifying whether the AMO/NAO or global mean temperatures are the cause of heat wave variability would require the analysis of appropriate climate model experiments [17] and is beyond the scope of the present study. Other large-scale indices moderate summer temperatures in Europe [20], but their effects appear to be weaker than those of the AMO and summertime NAO. Nevertheless, the statistical model could be extended to incorporate other indices and quantify their possible effects on UK heat wave numbers and lengths.

The patterns of SSTs in the North Atlantic have changed in recent years, with a cold anomaly in the subpolar gyre and a warm anomaly in the subtropics [35]. A similar cold anomaly was last present during the 1990s when the AMO index was negative and the subtropical SSTs were also cooler than average [36]. The AMO index is typically calculated using SSTs over $20^{\circ} \mathrm{N}$ to $70^{\circ} \mathrm{N}$, and so does not represent these strong meridional gradients in SSTs well. Such gradients may lead to increased storminess over Europe [36]. The impact of these SST gradients on UK heat waves is unclear. In 2015, much of central Europe experienced prolonged periods of very high temperatures which have been partly attributed to the strong SST gradient in the north Atlantic [35]. In contrast, the UK only experienced a single very warm day ( 1 July 2015) when temperatures over $30^{\circ} \mathrm{C}$ were recorded much of England. Heat waves in the UK in 2015 were shorter in length than those in other years between 2010 and 2016 and were confined to south east England. Nevertheless, the statistical model could be extended to include these cold SST anomalies, either as a simple binary flag or by the meridional SST gradient, as another possible indicator of a summer heat wave. Another study [22] showed that both the mega-El Niño/Southern Oscillation (mega-ENSO) and the AMO modulated the number of heat wave days (HWF) over Europe on decadal timescales, although the effect of the AMO was larger. The statistical model could be extended to include the mega-ENSO.

\section{Conclusions}

Increasing numbers and lengths of heat waves have been inferred from temperatures recorded at weather stations the UK. These results are consistent with similar studies of heat waves in continental Europe. Changes in heat wave lengths at some stations were found to be more complex than suggested by a simple linear trend. The lengths of very long heat waves (over 10 days in length) declined from the mid-1970s to the present day, whereas the lengths of shorter heat waves (up to 10 days) have increased slightly over a similar period.

High multi-decadal variability in numbers and lengths of UK heat waves were identified at all stations. A logistic regression model was constructed which suggested an association between the sign and magnitude of the AMO and summertime NAO indices and numbers and lengths of heat waves. The AMO had a larger effect than the NAO. These results were robust to different temperature thresholds used to define heat waves and combinations of datasets of the AMO and summertime NAO.

Variations in the AMO and summertime NAO therefore appear to moderate the numbers and lengths of heat waves in the UK. The AMO is currently in marginally negative phase, but could become more negative. Any effects of a warming climate on heat waves in the UK in the near future could be moderated by changes in the AMO.

Supplementary Materials: Supplementary materials can be found at www.mdpi.com/2073-4433/8/10/191/s1.

Acknowledgments: This work was funded under the National Institute for Health Research Health Protection Research Unit (NIHR HPRU) in environmental change and health, led by the London School of Hygiene and Tropical Medicine in partnership with Public Health England (PHE), the University of Exeter and the Met Office. The authors would like to thank KNMI and NOAA for enabling access to the climate indices and John Kennedy for calculating one of the series of the Atlantic Meridional Oscillation used in this study.

Author Contributions: M.G.S. conceived the study and designed the experiments. S.E.O.J. identified the weather stations. M.G.S., K.H.S. and S.E.O.J. analysed the data. T.E. designed the logistic regression model and guided the interpretation of the results. M.G.S. wrote the paper with substantial input from T.E., K.H.S. and S.E.O.J. 
Conflicts of Interest: The authors declare no conflict of interest. The funding sponsors had no role in the design of the study; in the collection, analyses, or interpretation of data; in the writing of the manuscript, and in the decision to publish the results.

\section{Appendix A}

Locations and Data Periods of the 29 Weather Stations Selected for Study

Table A1. The 29 weather stations selected for study. All stations were operational up to and including 2016 and had near-continuous daily temperature data available from 1931 or earlier.

\begin{tabular}{|c|c|c|c|c|}
\hline Station Name & Latitude & Longitude & Country $^{a}$ & Data From \\
\hline Aldergrove & 54.6636 & -6.22436 & NI & 1930 \\
\hline Armagh & 54.3523 & -6.64866 & $\mathrm{NI}$ & 1865 \\
\hline Balmoral & 57.0375 & -3.21897 & $\mathrm{SCO}$ & 1918 \\
\hline Bradford & 53.8134 & -1.77234 & ENG & 1908 \\
\hline $\begin{array}{c}\text { Cambridge, Botanic } \\
\text { Gardens }\end{array}$ & 52.1935 & 0.13113 & ENG & 1911 \\
\hline Craibstone & 57.1868 & -2.21323 & $\mathrm{SCO}$ & 1931 \\
\hline Cranwell & 53.0309 & -0.50194 & ENG & 1930 \\
\hline Cromer & 52.9332 & 1.29273 & ENG & 1902 \\
\hline Douglas & 54.168 & -4.48022 & IOM & 1878 \\
\hline Durham & 54.7679 & -1.58455 & ENG & 1880 \\
\hline Eastbourne & 50.7617 & 0.28543 & ENG & 1911 \\
\hline Lerwick & 60.1395 & -1.18299 & $\mathrm{SCO}$ & 1930 \\
\hline Leuchars & 56.3775 & -2.86051 & $\mathrm{SCO}$ & 1921 \\
\hline London, St James's Park & 51.5043 & -0.12948 & ENG & 1903 \\
\hline Morecambe No 2 & 54.0762 & -2.85825 & ENG & 1930 \\
\hline Morpeth, Cockle Park & 55.2129 & -1.68615 & ENG & 1897 \\
\hline Newton Rigg & 54.6699 & -2.78644 & ENG & 1906 \\
\hline Oxford & 51.7607 & -1.2625 & ENG & 1853 \\
\hline Plymouth Mountbatten ${ }^{b}$ & 50.3544 & -4.11986 & ENG & 1874 \\
\hline Rothamsted & 51.8062 & -0.35858 & ENG & 1916 \\
\hline Sheffield & 53.38128 & -1.48986 & ENG & 1882 \\
\hline Shoeburyness ${ }^{b}$ & 51.53606 & 0.80914 & ENG & 1930 \\
\hline Skegness & 53.1476 & 0.34797 & ENG & 1904 \\
\hline Stornoway Airport & 58.2138 & -6.31772 & $\mathrm{SCO}$ & 1873 \\
\hline Teignmouth & 50.5451 & -3.49487 & ENG & 1931 \\
\hline Tiree & 56.49982 & -6.8796 & $\mathrm{SCO}$ & 1930 \\
\hline Valley & 53.2524 & -4.53524 & WAL & 1930 \\
\hline Wick Airport & 58.4541 & -3.0884 & $\mathrm{SCO}$ & 1930 \\
\hline Wisley & 51.3103 & -0.47478 & ENG & 1904 \\
\hline
\end{tabular}

a NI-Northern Ireland; SCO—Scotland; ENG—England; WAL—Wales; IOM-Isle of Man. ${ }^{\mathrm{b}}$ Data from two or more stations were combined into a single series; see Section S2 for further details. 

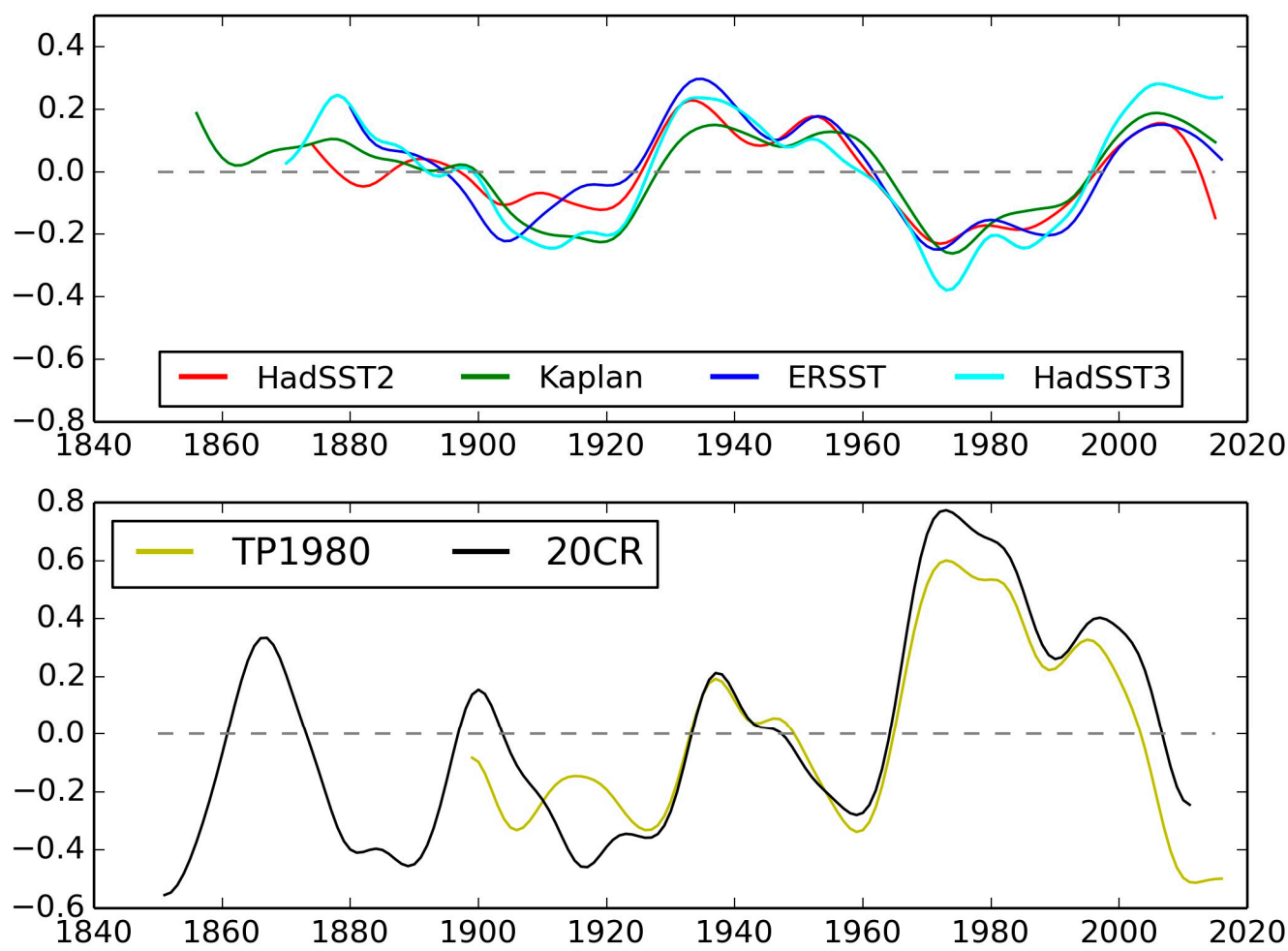

Figure A1. Smoothed time series of the AMO (upper panel) and summertime NAO (lower panel). The data sources are listed in Table S4.

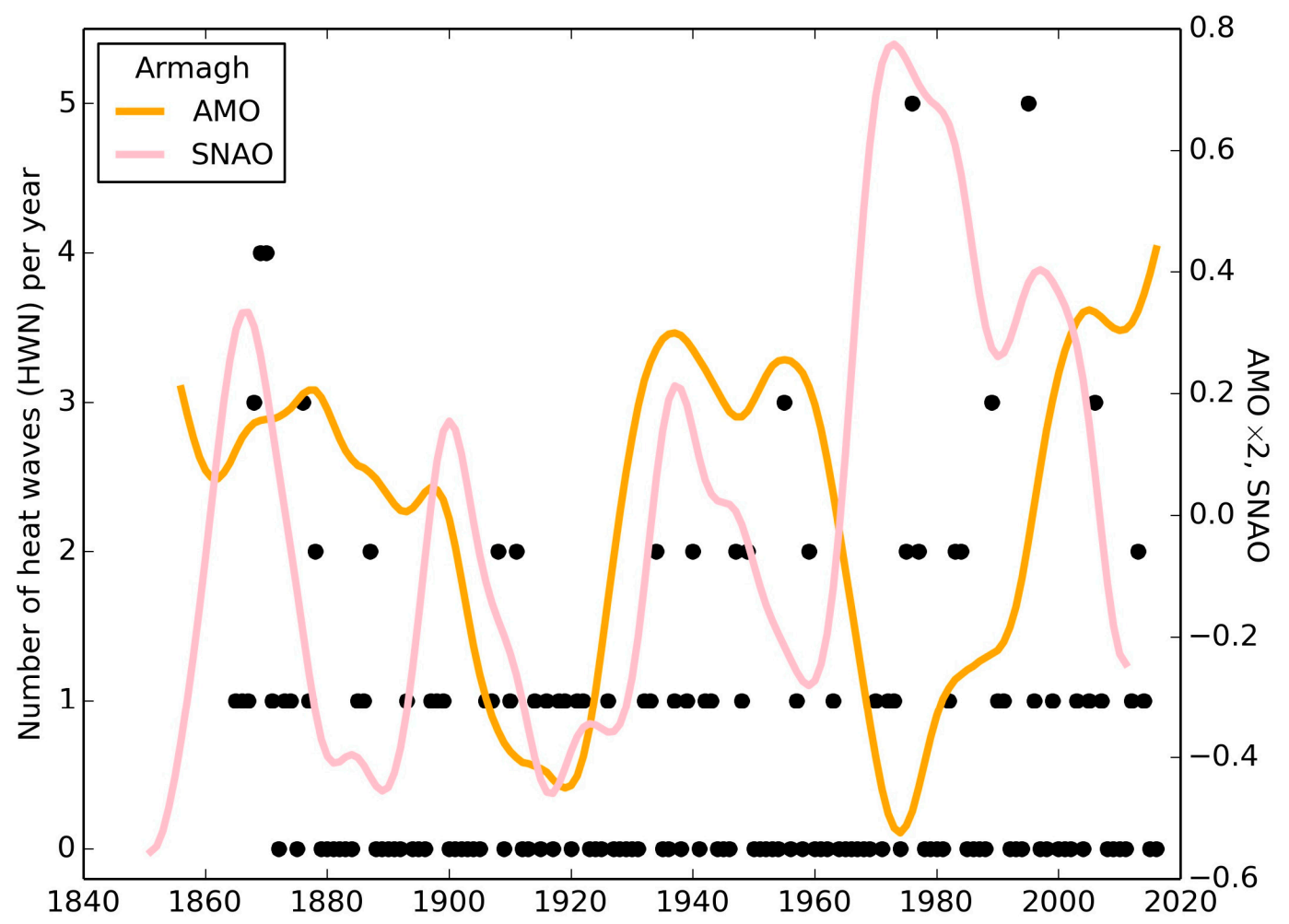

Figure A2. Smoothed series of the AMO (orange line) and summertime NAO (pink line), together with the numbers of heat waves per year for Armagh (solid circles) identified using the 98th percentile threshold temperature. The values of the AMO index have been doubled for clarity. 


\section{References}

1. D'Ippoliti, D.; Michelozzi, P.; Marino, C.; de'Donato, F.; Menne, B.; Katsouyanni, K.; Kirchmayer, U.; Analitis, A.; Medina-Ramón, M.; Paldy, A.; et al. The impact of heat waves on mortality in 9 European cities: Results from the EuroHEAT project. Environ. Health 2010, 9, 37. [CrossRef] [PubMed]

2. Dobney, K.; Baker, C.J.; Quinn, A.D.; Chapman, L. Quantifying the effects of high summer temperatures due to climate change on buckling and rail related delays in south-east United Kingdom. Meteorol. Appl. 2009, 6, 245-251. [CrossRef]

3. Van Vliet, M.T.H.; Ludwig, F.; Zwolsman, J.J.G.; Weedon, G.P.; Kabat, P. Global river temperatures and sensitivity to atmospheric warming and changes in river flow. Water Resour. Res. 2011, 47, W02544. [CrossRef]

4. Johnk, K.D.; Huisman, J.; Sharples, J.; Sommeijeri, B.; Visser, P.M.; Strooms, J.M. Summer heat-waves promote blooms of harmful cyanobacteria. Glob. Chang. Biol. 2008, 14, 495-512. [CrossRef]

5. Della-Marta, P.M.; Haylock, M.R.; Luterbacher, J.; Wanner, H. Doubled length of western European summer heat waves since 1880. J. Geophys. Res. 2007, 112. [CrossRef]

6. Labajo, Á.L.; Egido, M.; Martin, Q.; Labajo, J.; Labajo, J.L. Definition and temporal evolution of the heat and cold waves over the Spanish Central Plateau from 1961 to 2010. Atmósfera 2014, 27, 273-286. [CrossRef]

7. Brugnara, Y.; Auchmann, R.; Brönnimann, S.; Bozzo, A.; Berro, D.C.; Mercalli, L. Trends of mean and extreme temperature indices since 1874 at low-elevation sites in the southern Alps. J. Geophys. Res. Atmos. 2016, 121, 3304-3325. [CrossRef]

8. Bartoszek, K.; Krzyżewska, A. The atmospheric circulation conditions of the occurrence of heatwaves in Lublin, southeast Poland. Weather 2016, 72, 176-180. [CrossRef]

9. Morabito, M.; Crisci, A.; Messeri, A.; Messeri, G.; Betti, G.; Orlandini, S.; Raschi, A.; Maracchi, G. Increasing heatwave hazards in the southeastern European Union capitals. Atmosphere 2017, 8, 115. [CrossRef]

10. Shevchenko, O.; Lee, H.; Snizhko, S.; Mayer, H. Long-term analysis of heat waves in Ukraine. Int. J. Climatol. 2014, 34, 1642-1650. [CrossRef]

11. Beniston, M. The 2003 heat wave in Europe: A shape of things to come? An analysis based on Swiss climatological data and model simulations. Geophys. Res. Lett. 2004, 31, L02202. [CrossRef]

12. Parker, D.E.; Horton, E.B. Uncertainties in the Central England Temperature series since 1878 and some changes to the maximum and minimum series. Int. J. Climatol. 2005, 25, 1173-1188. [CrossRef]

13. Hulme, M.; Jenkins, G.J.; Lu, X.; Turnpenny, J.R.; Mitchell, T.D.; Jones, R.G.; Lowe, J.; Murphy, J.M.; Hassell, D. Climate Change Scenarios for the United Kingdom: The UKCIP02 Scientific Report; Tyndall Centre for Climate Change Research, School of Environmental Sciences, University of East Anglia: Norwich, UK, 2002; p. 120.

14. Perkins, S.E.; Alexander, L.V. On the measurement of heat waves. J. Clim. 2013, 26, 4500-4517. [CrossRef]

15. Knight, J.R.; Folland, C.K.; Scaife, A.A. Climate impacts of the Atlantic Multidecadal Oscillation. Geophys. Res. Lett. 2006, 33, L17706. [CrossRef]

16. Chylek, P.; Klett, J.D.; Lesins, G.; Dubey, M.K.; Hengartner, N. The Atlantic Multidecadal Oscillation as a dominant factor of oceanic influence on climate. Geophys. Res. Lett. 2014, 41, 1689-1697. [CrossRef]

17. Della-Marta, P.M.; Luterbacher, J.; von Weissenfluh, H.; Xoplaki, E.; Brunet, M.; Wanner, H. Summer heat waves over western Europe 1880-2003, their relationship to large-scale forcings and predictability. Clim. Dyn. 2007, 29, 251-275. [CrossRef]

18. Cropper, T.; Cropper, P.A. 133-year record of climate change and variability from Sheffield, England. Climate 2016, 4, 46. [CrossRef]

19. Folland, C.K.; Knight, J.; Linderholm, H.W.; Fereday, D.; Ineson, S.; Hurrell, J.W. The summer North Atlantic Oscillation: Past, present, and future. J. Clim. 2009, 22, 1082-1103. [CrossRef]

20. Rust, H.W.; Richling, A.; Bissolli, P.; Ulbrich, U. Linking teleconnection patterns to European temperature-A multiple linear regression model. Meteorol. Z. 2015, 24, 411-423. [CrossRef]

21. Kenyon, J.; Hegerl, G.C. Influence of modes of climate variability on global temperature extremes. J. Clim. 2008, 21, 3872-3889. [CrossRef]

22. Zhou, Y.; Wu, Z. Possible impacts of mega-El Niño/Southern Oscillation and Atlantic Multidecadal Oscillation on Eurasian heatwave frequency variability. Q. J. R. Meteorol. Soc. 2016, 142, 1647-1661. [CrossRef]

23. Met Office Integrated Data Archive System (MIDAS) Land and Marine Surface Stations Data (1853-Current). NCAS British Atmospheric Data Centre. Available online: http://catalogue.ceda.ac.uk/ uuid/220a65615218d5c9cc9e4785a3234bd0 (accessed on 27 March 2017). 
24. Venables, W.N.; Ripley, B.D. Modern Applied Statistics with S, 4th ed.; Springer: New York, NY, USA, 2002.

25. Van Oldenborgh, G.J.; te Raa, L.A.; Dijkstra, H.A.; Philip, S.Y. Frequency- or amplitude-dependent effects of the Atlantic meridional overturning on the tropical Pacific Ocean. Ocean Sci. 2009, 5, 293-301. [CrossRef]

26. Enfield, D.B.; Mestas-Nunez, A.M.; Trimble, P.J. The Atlantic Multidecadal Oscillation and its relationship to rainfall and river flows in the continental U.S. Geophys. Res. Lett. 2001, 28, 2077-2080. [CrossRef]

27. Kennedy, J.J.; Rayner, N.A.; Smith, R.O.; Saunby, M.; Parker, D.E. Reassessing biases and other uncertainties in sea-surface temperature observations since 1850 part 2: Biases and homogenisation. J. Geophys. Res. 2011, 116, D14104. [CrossRef]

28. Knight, J.R.; Allan, R.J.; Folland, C.K.; Vellinga, M.; Mann, M.E. A signature of persistent natural thermohaline circulation cycles in observed climate. Geophys. Res. Lett. 2005, 32, L20708. [CrossRef]

29. Trenberth, K.E.; Paolino, D.A. The Northern Hemisphere sea level pressure data set: Trends, errors, and discontinuities. Mon. Weather Rev. 1980, 108, 855-872. [CrossRef]

30. Compo, G.P.; Whitaker, J.S.; Sardeshmukh, P.D. The Twentieth Century Reanalysis Project. Q. J. R. Meteorol. Soc. 2001, 137, 1-28. [CrossRef]

31. R Core Team. R: A Language and Environment for Statistical Computing; R Foundation for Statistical Computing: Vienna, Austria, 2016; Available online: https:/ / www.R-project.org/ (accessed on 8 August 2017).

32. Plummer, M. Rjags: Bayesian Graphical Models Using MCMC, R Package Version 4-4, 2015. Available online: https: / / cran.r-project.org/ package=rjags (accessed on 30 August 2016).

33. IPCC. Summary for Policymakers. In Climate Change 2013: The Physical Science Basis. Contribution of Working Group I to the Fifth Assessment Report of the Intergovernmental Panel on Climate Change; Stocker, T.F., Qin, D., Plattner, G., Tignor, M., Allen, S.K., Boschung, J., Nauels, A., Xia, Y., Bex, V., Midgley, P.M., Eds.; Cambridge University Press: Cambridge, UK; New York, NY, USA, 2013; pp. 1-30.

34. Vecchi, G.A.; Delworth, T.L.; Booth, B. Climate science: Origins of Atlantic decadal swings. Nature 2017, 548, 284-285. [CrossRef] [PubMed]

35. Duchez, A.; Frajka-Williams, E.; Josey, S.A.; Evans, D.G.; Grist, J.P.; Marsh, R.; McCarthy, G.D.; Sinha, B.; Berry, D.I.; Hirschi, J.J.-M. Drivers of exceptionally cold North Atlantic Ocean temperatures and their link to the 2015 European heat wave. Environ. Res. Lett. 2016, 11, 074004. [CrossRef]

36. Frajka-Williams, E.; Beaulieu, C.; Duchex, A. Emerging negative Atlantic Multidecadal Oscillation index in spite of warm subtropics. Sci. Rep. 2017, 7, 11224. [CrossRef] [PubMed] 